УДК 811.124+378.111

DOI: $10.26435 /$ UC.V0I4(29).258

\author{
Е.А. Косенкова-Дудник, О.В. Партас, И.С. Еромянц
}

ГОО ВПО «Донецкий национальный медицинский университет имени М. Горького», Донецк

\title{
РОЛЬ ДЕКАНАТА В РЕАЛИЗАЦИИ КОМПЕТЕНТНОСТНОГО ПОДХОДА ПРИ ФОРМИРОВАНИИ ЛИЧНОСТИ БУДУЩЕГО ВЫПУСКНИКА
}

В основе нового государственного стандарта высшего профессионального образования лежит компетентностный подход, согласно которому приоритетной задачей образования становится формирование профессиональных и общекультурных компетенций будущего специалистамедика. Изменения целей образования связаны с новыми требованиями, предъявляемыми к деятельности выпускника вуза в современных условиях. Понятие «компетенция» выступило «в качестве общего определения интегрального социально-личностно-поведенческого феномена как результата образования в совокупности мотивационно-ценностных, когнитивных составляющих», что позволяет говорить не просто о модернизации учебного процесса, а о переходе к новой образовательной парадигме [1].

Компетентность специалиста предполагает не только наличие профессиональных знаний, умений и навыков, но и готовность реализовывать знания, опыт, личностные качества в профессиональной сфере, осознавать социальную значимость и личную ответственность за результаты своей деятельности, понимать необходимость постоянного совершенствования, проявлять конкурентоспособность на рынке труда. С точки зрения компетентностного подхода, уровень образованности специалиста определяется способностью самостоятельно решать задачи и проблемы различного уровня сложности на основе имеющихся знаний, т.е. внимание акцентируется на способности применения полученных знаний, умений и навыков в конкретных ситуациях.

Выпускник вуза призван реализовать себя не только в узкой профессиональной области, но и в сложной и многогранной системе социальных и межличностных связей и отношений. Общество видит в специалисте с высшим образованием носителя высокого уровня культуры, прочно сформировавшейся системы нравственных ценностей, гражданских качеств, активной жизненной позиции. Поэтому понятие «компе- тентность» является интегральным и характеризует человеческую деятельность в различных сферах.

Задача высшей медицинской школы - это формирование личности, в которой профессиональное и нравственное начала находятся в единстве, не противоречат друг другу [2].

Высшие учебные заведения имеют особый и своего рода решающий статус, от которых зависит окончательное формирование и становление личности, как полноправного члена социума, имеющего право на общественно-полезный труд, создание семьи, рождение и воспитание своего поколения. Главными инструментами при этом являются специфические знания, которые невозможно получить в «семейной ячейке». Накопление таких знаний дает возможность приобрести профессию и занять свое достойное место в обществе, ради которого современный человек способен преодолевать огромные расстояния и готов даже расплачиваться немалыми денежными средствами. Следовательно, образовательный процесс посредством обучения той или иной специальности является в этом случае довольно эффективным и стимулирующим фактором в становлении личности. Однако вырастить хорошего специалиста и вместе с тем благородного и добропорядочного человека удается не всегда [3].

\section{О БСУЖДЕНИЕ}

Несомненно, что любое высшее учебное заведение ставило и ставит перед собой первостепенную задачу - подготовить и воспитать высококвалифицированного специалиста. В медицинском университете, где объектом влияния является человек, качество будущего специалиста должно быть не на порядок, а значительно выше, чем в любом другом ВУЗе. Студент-медик должен иметь поликультурный тип личности:

() Е.А. Косенкова-Дудник, О.В. Партас, И.С. Еромянц, 2018 (c) Университетская Клиника, 2018 
обладать развитыми потребностями в познании окружающей действительности; понимать высокую ценность человеческой жизни; обладать развитым интеллектом, владеть новыми технологиями и умениями, которые необходимы для реализации его профессиональной деятельности. Конечная цель работы всех факультетов медицинского университета - выпуск квалифицированного врача, который будет способен решать глобальные задачи по охране и сохранению здоровья населения.

На каждом факультете работа со студентами организуется деканатами, которые совместно с кафедральными коллективами тесно работают со студентами на всех этапах их становления и как специалиста и как личности.

Выбор будущей специальности является важной задачей для выпускника школы. Зачастую определяющим критерием в этом выборе является профессиональная деятельность родителей. Создаются целые династии, немало их и среди медицинских работников. Меняются времена, меняются запросы, психология, социальный статус, материальная обеспеченность, а также личностные взаимоотношения. И теперь пример родителей, друзей и родственников не всегда воспринимается подрастающим поколением. Абитуриенту нужна квалифицированная помощь в выборе профессии, которой он посвятит свое будущее. Для этого на каждом факультете работает комиссия по профессиональной ориентации, главной задачей которой - помочь выпускнику образовательных школ, лицеев, медицинских училищ в выборе своего призвания. В комиссию входят наиболее заслуженные специалисты факультета, имеющие высокий авторитет и ответственность за будущие медицинские кадры. Преподавателями факультета организуются встречи с выпускниками школ как в г. Донецке, так и всей Донецкой Народной Республики. К этой работе активно привлекаются студентыактивисты деканата, старшекурсники факультета, которые участвуют в собраниях со старшеклассниками школ, в том числе школ, где они учились ранее. На этих встречах рассказ бывшего выпускника школы о своей профессии, порой не легком достижении цели, воспринимается школьником совершенно по-особенному, не так как на других собраниях. Будущий абитуриент может оценить свои возможности для поступления в университет, и, что очень важно, имеет информацию на изучение каких дисциплин необходимо обратить первостепенное внимание, какие качества следует в себе развивать и совершенствовать. Старшеклассник более ответственно и осознанно подходит к выбору своей будущей профессиональной деятельности.
Следующим немаловажным шагом в создании будущего высококвалифицированного специалиста-медика является формирование квалифицированного состава приемной комиссии. Слаженность работы этого подразделения университета, корректность, деловитость, заинтересованность в судьбе каждого будущего студента не остаются без следа. Все это накладывает на абитуриента отпечаток «внутреннего стержня» коллектива университета в целом. Став студентом, он уже получил заряд воспитательной энергии и его нужно развивать дальше. Тот же, кто потерпел фиаско, получает максимум информации, как подготовиться для будущего поступления, какие есть возможности, чтобы на следующий год воплотить свои идеи и не потеряться для ВУЗа. Для этого есть возможность подготовиться на факультете довузовской подготовки и повторить попытку в достижении своей цели. Элементы такой заботы уже являются этапом воспитания. Такой абитуриент видит заинтересованность в нем и старается оправдать такое доверие.

Успех работы врача, как правило, зависит от работы целого коллектива медицинских работников. Навыки такой работы должны формироваться с первых дней обучения в университете, с первых дней работы студента в студенческой группе. Деканатом скрупулезно и ответственно проводится работа по формированию первого трудового коллектива студентов. Ведь именно коллектив, в первую очередь, играет существенную роль в воспитании личности будущего врача. Группы должны формироваться с учетом интересов, наклонностей и способностей студентов несмотря на то, что первоначальная информация о них крайне ограничена. Каждый из них пришел в ВУЗ со своим уровнем знаний, своими амбициями и задачами, которые всегда индивидуальны. В группе должна быть создана общая атмосфера заинтересованности в получении будущей профессии. Все это начинается еще до начала учебного года. На факультете ежегодно в торжественной обстановке проводится посвящение в студенты. Вчерашние выпускники школ коллективно дают торжественное обещание хорошо учиться, хранить и обогащать традиции ВУЗа, помогать друг другу в учебе на пути свершения своих мечтаний. В торжественной обстановке студенты получают свой первый документ, который приобщает их к большой семье медицинских работников - студенческий билет, по команде ректора одевают медицинскую форму, честь которой будут отстаивать на протяжении всей своей жизни. Сама торжественная атмосфера, присутствие на этом мероприятии профессорско-преподавательского состава уни- 
верситета, дают значительный задел и толчок в воспитательной работе, который должен постоянно поддерживаться и совершенствоваться.

С первых дней учебы в университете студент сталкивается с новой системой обучения, которая существенно отличается от школьной. И в этот момент неоценима работа куратора студенческой группы, благодаря которому обеспечивается адаптация вчерашнего школьника, выпускника медицинского училища, стажированного младшего медицинского персонала к работе в качестве студента медицинского университета. С первых дней учебы студент работает на свое будущее - на получение квалификации специалиста-медика. Деканат в сотрудничестве с кураторами групп организуют производственные собрания групп, курсов, факультета по вопросам организации педагогического процесса, выбора старост, членов совета самоуправления.

С первых дней университетской жизни студент имеет возможность участвовать в управлении университетом через органы студенческого самоуправления. Самоуправление студентов является очень важным рычагом воспитательной работы, так как эта работа связана с большой ответственностью студентов перед всем университетским коллективом, а не только получение возможности участия в культмассовых, спортивных и других мероприятиях. Студенческое самоуправление участвует в принятии решений о поощрении студентов, наложении взысканий, отчислении студентов по различным причинам.

Основным блоком работы деканата, который имеет значительную воспитательную составляющую, является работа по организации учебы студенческого коллектива. С первых дней учебы студент понимает, что факультет - это большая семья, а ее составляющие - деканат, кафедральные коллективы и студенты, делают одно общее дело - создают высококвалифицированного специалиста, обладающего качествами разносторонне развитого человека.

Организация процесса обучения на факультете сопряжена с рядом формальных требований, которые довольно жестко и неукоснительно контролируются деканатом - посещение занятий по расписанию, обязательность медицинской формы, обязательность знаний (а не только наличие студента в учебной комнате), необходимость отработки занятий, пропущенных даже по уважительной причине и т.д. Такой подход, выработанный и апробированный на практике многими поколениями сотрудников деканата, позволяет максимально ускорить переход студента к взрослой жизни, максимально облегчает адаптацию студентов к летней про- изводственной практике, к работе в качестве среднего медицинского персонала в лечебнопрофилактических учреждения страны.

Значительную воспитательную роль составляет совместная работа деканата, студенческого самоуправления и самого студента по сохранению студенческого коллектива в семестре, предсессионный период и сессию. Это работа по улучшению успеваемости, минимизации пропусков занятий и профилактике отчислений студентов. В этом велика роль личности декана и заместителя деканата. Такая совместная работа меняет отношение многих студентов к учебе, к будущей профессиональной деятельности, повышает их ответственность за результаты успеваемости.

Здоровая конкуренция среди студентов факультета является стимулом к всестороннему развитию каждого студента независимо от показателей успеваемости в доуниверситетский период. Результаты успешности обучения в семестре и во время сессии являются объективным критерием выдвижения на поощрение в виде именной стипендии, повышенной стипендии, надбавок к стипендии, повышают авторитет данного студента среди профессорскопреподавательского состава и обучающихся на факультете. Такие студенты показывает личный пример и имеют право требовать с других студентов улучшение успеваемости.

Врач - это не только высококвалифицированный специалист, а и ученый, который всю профессиональную жизнь занимается наукой. Университет является тем местом, которое дает возможность студенту получить навыки постановки цели и задач научного исследования, выбора методов исследования, получения репрезентативных результатов, методов обработки и анализа данных, формулировки выводов и рекомендаций. Деканат и кафедральные коллективы организуют работу студенческого научного общества. Выполняя научные исследования, студент использует знания, полученные в университете, и материалы медицинской науки на данный исторический момент.

На воспитание должна работать заинтересованность в его жизни со стороны деканата, ВУЗа, студенческого коллектива. Не остается без внимания проблема обеспеченности студентов жильем. Помощник декана по воспитательной работе совместно с кураторами проводят работу во внеаудиторное время - организуют досуг и быт в общежитии. Проводятся соревнования по различным видам спорта, викторины, конкурсы на лучшие комнаты общежития.

Воспитание студентов невозможно без совместной работы деканата и родителей. Нель- 
зя исключать воспитательную роль родителей и родственников в период обучения студента в университете. Это должно делаться аккуратно, сотрудники деканата должны помнить, что для них студент есть студент, а для родителей дитя на всю жизнь. В личных беседах с родителями должны быть соблюдены все деонтологические аспекты. При этом должны быть объективно оценены способности и возможности студента, и декан должен дать совет родителям, не унижая достоинство студента, не забирая у студента возможности достичь своей мечты. Все это оценит будущий специалист.

Одним из самых важных моментов в профессиональном становлении будущего врача является летняя производственная практика (ЛПП). Корректная организация ЛПП с точки зрения оптимального выбора разнопрофильных баз практики, высококвалифицированных специалистов - руководителей ЛПП облегчает студентам не только освоение практических навыков, но и дает возможность ознакомления с различными специальностями в медицине, а значит облегчает им выбор будущей специализации.

Ответственным шагом в воспитании является участие деканата в подготовке и проведении итоговой государственной аттестации. Деканат и кафедры организуют дополнительные занятия и тренинги. Однако, подготовка к итоговой аттестации не может сводиться только к «натаскиванию» на теоретический материал и на механическую отработку практических навыков. Важна роль деканата в психологической поддержке выпускника, в умении мобилизовать все его знания и опыт, полученные им за шесть лет обучения в университете, при решении заданий итоговой государственной аттестации. Это еще один практический шаг к воспитанию квалифицированного врача.

Завершается обучение в университете вручением диплома о высшем медицинском образовании. Ежегодно деканат с участием ректората проводит большую работу в этом направлении. Ведь важно не только как прошел свой студенческий путь выпускник, но и как он его завершил. Должно быть учтено все: порядок вручения дипломов, поощрение отличников, приня- тие присяги врача, поздравления, ответное слово, концертная часть и т.д. Самое важное, наверное, это принятие клятвы врача. В течение ряда лет каждый выпускник делает это в своей будущей «профессиональной», «рабочей» форме врачебный халат, каждый оставляет подпись на тексте клятвы врача, которая остается в личном деле выпускника.

Как правило, выпускниками не прерывается связь и по окончании ВУЗа. Профессия врача требует у молодого специалиста постоянного контакта с коллегами, часто возникают ситуации, требующие консультации у ведущих специалистов, которыми являются преподаватели университета. Деканат и руководство университета продолжает свою работу по воспитанию специалистов, организуя последипломный этап обучения и ежегодное повышение квалификации врачей.

\section{З А К ЛЮЧЕ НИЕ}

Обучение и воспитание - взаимосвязанные процессы. Воспитание всегда ориентировалось, прежде всего, на подрастающее поколение, на молодежь. Наша задача проводить воспитательную работу со студентами не только во время учебы, но и во внеурочное время, чтобы по окончании вуза мы могли сказать, что подготовили конкурентоспособного специалиста, обладающего гуманизмом, принципиальной гражданской позицией и высокими моральнонравственными качествами. Успешность обучения студентов в университете во многом зависит от реальных условий их жизнедеятельности, характером возникающих в процессе учебы проблем и возможностям их разрешения со стороны администрации и деканата. Только учить - это мало, надо еще и воспитывать. Высшее образование не может быть сведено лишь к обучению, оно требует целенаправленного воспитания молодого поколения. Профессиональное обучение и воспитание должны слиться в органический процесс становления профессиональной компетентности специалиста с университетским уровнем культуры и формирования его личности. 


\section{Е.А. Косенкова-Дудник, О.В. Партас, И.С. Еромянц}

ГОО ВПО «Донецкий национальный медицинский университет имени М. Горького», Донецк

\section{РОЛЬ ДЕКАНАТА В РЕАЛИЗАЦИИ КОМПЕТЕНТНОСТНОГО ПОДХОДА ПРИ ФОРМИРОВАНИИ ЛИЧНОСТИ БУДУЩЕГО ВЫПУСКНИКА}

В медицинском университете, где объектом влияния является человек, качество будущего специалиста должно быть не на порядок, а значительно выше, чем в любом другом высшем учебном заведении. Студент-медик должен иметь поликультурный тип личности: обладать развитыми потребностями в познании окружающей действительности, понимать высокую ценность человеческой жизни, обладать развитым интеллектом. Конечная цель работы всех факультетов медицинского университета - выпуск квалифицированного врача, который будет способен решать глобальные задачи по охране и сохранению здоровья населения. На каждом факультете работа со студентами организуется деканатами, которые совместно с кафедральными коллективами тесно работают со студентами на всех этапах их становления и как специалиста и как личности.

Выбор будущей специальности является важной задачей для выпускника школы. Абитуриенту нужна квалифицированная помощь в выборе профессии, которой он посвятит свое будущее. Для этого на каждом факультете работает комиссия по профессиональной ориентации, главной задачей которой - помочь выпускнику образовательных школ, лицеев, медицинских училищ в выборе своего призвания.

Следующим немаловажным шагом в создании будущего высококвалифицированного специалистамедика является формирование квалифицированного состава приемной комиссии.

Успех работы врача, как правило, зависит от работы целого коллектива медицинских работников. Деканатом скрупулезно и ответственно проводится работа по формированию первого трудового коллектива студентов.

С первых дней учебы в университете студент сталкивается с новой системой обучения, которая суще- ственно отличается от школьной. И в этот момент неоценима работа куратора студенческой группы, благодаря которому обеспечивается адаптация вчерашнего школьника к работе в качестве студента медицинского университета

Врач - это не только высококвалифицированный специалист, а и ученый, который всю профессиональную жизнь занимается наукой. Деканат и кафедральные коллективы организуют работу студенческих научных обществ.

Воспитание студентов невозможно без совместной работы деканата и родителей. Нельзя исключать воспитательную роль родителей и родственников в период обучения студента в университете.

Как правило, выпускниками не прерывается связь и по окончании ВУЗа. Профессия врача требует у молодого специалиста постоянного контакта с коллегами. Деканат и руководство университета продолжает свою работу по воспитанию специалистов, организуя последипломный этап обучения и ежегодное повышение квалификации врачей.

Успешность обучения студентов в университете во многом зависит от реальных условий их жизнедеятельности, характером возникающих в процессе учебы проблем и возможностям их разрешения со стороны администрации и деканата. Только учить - это мало, надо еще и воспитывать. Высшее образование не может быть сведено лишь к обучению, оно требует целенаправленного воспитания молодого поколения. Профессиональное обучение и воспитание должны слиться в органический процесс становления профессиональной компетентности специалиста с университетским уровнем культуры и формирования его личности.

Ключевые слова: компетентностный подход, личность, специалист, воспитание, деканат.

\section{E.A. Kosenkova-Dudnik, O.V. Partas, I.S. Eromiants}

SEI HPE «M. Gorky Donetsk National Medical University», Donetsk

\section{THE ROLE OF THE DEAN'S OFFICE IN THE COMPETENCY-BASED APPROACH REALIZATION IN THE FORMATION OF THE FUTURE GRADUATE PERSONALITY}

At the medical university where the object of influence is a person, the quality of the future specialist should be much higher than in any other higher educational institutions. A medical student must have a multicultural personality type: to have developed needs for cognition of the surrounding reality, understand the high value of human life, have a developed intellect. The ultimate goal of the work of all faculties of the medical university is graduation of a qualified doctor who will be able to solve global problems of protecting and preserving health of the population. At each faculty, work with students is organized by the dean's offices with the department staffs that work closely with students at all stages of their formation, both as a specialist and as a person.

The choice of future specialty is an important task for the school graduate. The applicant needs a qualified help in choosing a profession which he will devote his future to. A vocational guidance commission works at each faculty to help a graduate of education schools, lyceums, medical schools in choosing his calling.

The next important step in creating the future of a highly qualified medical specialist is the formation of a qualified admission committee.

As a rule, the success of the doctor's work depends on the work of the whole team of medical workers. Dean's office carries out carefully formation of the first working students' group.

The student is faced with a new training system which differs significantly from the school system from the first days of study at the university. And at this moment the 
work of the tutor of the student group is invaluable, thanks to which yesterday's schoolboy is adapted to work as a student of medical university.

A doctor is not only a highly qualified specialist, but also a scientist who takes part in science during his professional life. The dean's office and department staffs organize the work of student scientific societies.

Students' upbringing is impossible without dean's office and parents' cooperation. It is impossible to exclude the upbringing role of parents and relatives during studying period at the university.

As a rule, graduates do not interrupt their communication at the end of the university. The profession of the doctor requires keeping in touch with colleagues. The dean's office and the university management continue their work on educating specialists, organizing the post- graduate stage of education and annual training of doctors.

The success of teaching students at the university depends mostly on the real conditions of their life, the nature of the problems arising in the course of studies and the possibilities for their solving by the administration and the dean's office. Teaching is not enough, it is also necessary to bring up. Higher education cannot be reduced only to training, it requires upbringing of the younger generation. Professional training and education should merge into the organic process of specialist's professional competence formation with university cultural level and his personality formation.

Key words: competency-based approach, personality, specialist, upbringing, dean's office.

\section{ЛИТЕРАТУРА}

1. Алферова Е.А., Сущенко А.В., Плотникова И.Е. Роль воспитательного процесса в формировании поликультурной личности студента медицинского ВУЗА. Личность, семья и общество: вопросы педагогики и психологии: Сборник статей по материалам XXXIX международной научно-практической конференции. 2014; Ч. I, 4 (39): 64-68.

2. Овсянникова Е.К. Особенности формирования общекультурных компетенций студентов медицинского Вуза. Межд. журн. экспериментального образования. 2012; 4-2: 177-180.

3. Мачкалян Э.Л. Учебный процесс как фактор становления личности. Образование XXI века: Сборник материалов Международной научно-практической конференции; 2014. 590-593.

\section{REFERENCES}

1. Alferova E.A., Sushchenko A.V., Plotnikova I.E. Rol' vospitatel'nogo protsessa $\mathrm{v}$ formirovanii polikul'turnoi lichnosti studenta meditsinskogo VUZA. Lichnost', sem'ya i obshchestvo: voprosy pedagogiki i psikhologii: Sbornik statei po materialam XXXIX mezhdunarodnoi nauchnoprakticheskoi konferentsii. 2014; Ch. I, 4 (39): 64-68.

2. Ovsyannikova E.K. Osobennosti formirovaniya obshchekul'turnykh kompetentsii studentov meditsinskogo Vuza. Mezhd. zhurn. eksperimental'nogo obrazovaniya. 2012; 4-2: 177-180.

3. Machkalyan E.L. Uchebnyi protsess kak faktor stanovleniya lichnosti. Obrazovanie XXI veka: Sbornik materialov Mezhdunarodnoi nauchno-prakticheskoi konferentsii; 2014. 590-593. 